\title{
Introdução editorial
}

\section{Instituições e planejamento urbano e regional}

Anderson Cavalcante

Cedeplar/Universidade Federal de Minas Gerais

É com enorme prazer que apresento o número especial "Instituições e Planejamento Urbano e Regional", segundo produto da parceria entre a revista Nova Economia e o BDMG Cultural. A escolha do eixo temático deste volume não poderia ser mais natural, dado o lugar proeminente que a questão do planejamento urbano e regional ocupou ao longo da história tanto do BDMG quanto da Faculdade de Ciências Econômicas da UFMG, configurando assim um espaço fértil de diálogo entre ambas as instituições. Os trabalhos que compõem este número especial são resultado de discussões realizadas ao longo do $17^{\circ}$ Seminário sobre a Economia Mineira, promovido pelo Centro de Desenvolvimento e Planejamento Regional (Cedeplar) na cidade de Diamantina-MG, entre os dias 29 de agosto e 2 de setembro de 2016. O tradicional Seminário de Diamantina vem servindo, ele próprio, ao longo das últimas quatro décadas, como um importante espaço para reflexão sobre o tema do planejamento urbano e regional, e seu potencial como instrumento para superação das mazelas da sociedade brasileira. O país passou por significativas mudanças desde a criação do BDMG, mas uma das mais importantes foi o intenso processo de migração e urbanização de nossas cidades, um fenômeno de crescimento carregado de conflitos que invariavelmente se materializam no espaço. Paradoxalmente, os planos, as políticas públicas e o planejamento foram perdendo relevância ao longo desses anos, com alguns poucos pontos de resistência em algumas instituições. Nesse sentido, os artigos selecionados para o presente número ganham relevância, pois oferecem discussões sobre os rumos das instituições de desenvolvimento, em especial a evolução do planejamento urbano e regional, incluindo análises de novos fenômenos 
contemporâneos e seus efeitos espaciais, como o desenvolvimento sustentável, a exploração de recursos naturais, a participação popular democrática, a financeirização e a economia do conhecimento.

Em seu artigo "FACE/UFMG, BDMG E CEDEPLAR: Instituições do Planejamento e Desenvolvimento de Minas Gerais", João Antônio de Paula analisa a importância do Banco de Desenvolvimento de Minas Gerais (BDMG) no contexto histórico do desenvolvimento de Minas Gerais, em particular no que concerne o planejamento econômico e a organização institucional do estado. Ao BDMG, não coube apenas a realização de prospecções, avaliações e estudos para financiamento do crescimento, articulando também a criação de instituições públicas com esse fim, como a Fundação João Pinheiro. Esse papel central do BDMG na definição dos rumos institucionais do desenvolvimento de Minas Gerais foi compartilhado com a Faculdade de Ciências Econômicas (FACE) da UFMG e com o Cedeplar, instituições de ensino e pesquisa que aliavam capacidade técnica com uma abordagem pluralista em muito integrada aos requisitos particulares do desenvolvimento e do planejamento regional.

Ao longo dos 55 anos desde a criação do banco, os estudos em desenvolvimento e planejamento regional e urbano evoluíram, estando sujeitos não só ao contexto nacional, com ciclos de desenvolvimento variados, mas também à capacitação dos corpos técnico e acadêmico e à apropriação de matrizes teóricas diversas. O Seminário de Diamantina é um símbolo dessa evolução, reunindo estudos que denotam o estado da arte da produção de diversas instituições de Minas Gerais e do Brasil, propiciando o entendimento das novas realidades nacionais e regionais e apontando para rumos futuros. Nesse sentido, o artigo de Carlos Antônio Brandão intitulado "Espaços da destituição e as políticas urbanas e regionais no Brasil: uma visão panorâmica" nos proporciona um retrato da dinâmica da urbanização no Brasil, da evolução de seu aparato institucional-regulatório e das mudanças das políticas regionais e urbanas. $O$ artigo se encaixa neste volume como um importante compêndio da situação regional e urbana no país, visando suscitar a futura análise e discussão de casos mais específicos da dinâmica atual. Para Brandão, as persistentes desigualdades sociais no Brasil configuram uma máquina de produção de cidades que destitui e precariza sob a égide de uma regulação fraca ou, em alguns casos, simplesmente inexistente. Desse processo desigual decorre uma economia urbana com estrutura produtiva sofisticada, porém com heterogeneidades estrutu- 
rais significativas - uma urbanização que apresenta, de maneira paradoxal, traços ao mesmo tempo modernizantes e excludentes.

É possível compreender tal situação, de uma forma analítica e propositiva, a partir das próprias iniciativas de reflexão sobre o planejamento existentes e do papel ao qual a Universidade se propõe nesse debate. Assim como indicado no primeiro artigo deste número, o planejamento do desenvolvimento agrega diversas instituições públicas e privadas. Mas a Universidade possui um papel central nesse arranjo, não só pelo adensamento da perspectiva teórica, com ideias, estudos e proposições que subsidiam o debate, mas também como mediadora na interlocução entre as demandas sociais locais e os órgãos e instituições públicas de planejamento. $\bigcirc$ artigo "The university and metropolitan planning: an innovative experience", de Roberto Luís de Melo Monte-Mór, Geraldo Magela Costa, Heloisa Soares de Moura Costa e Marcos Gustavo Pires de Melo, trata de temática extremamente relevante e atual, apresentando uma reflexão teórica e política sobre a experiência em curso de planejamento metropolitano na Região Metropolitana de Belo Horizonte (RMBH), enfatizando o papel da Universidade na gestação dessa alternativa de planejamento. Fruto da discussão proposta na mesa redonda "Universidade e planejamento urbano/metropolitano", durante o 17o Seminário sobre a Economia Mineira, o artigo apresenta um processo inovador de planejamento urbano, embasado por learning by doing e metodologia coletivamente construída que contou com o suporte de estudos capitaneados por instituições acadêmicas como a UFMG, a PUC-MG e a UEMG. Trata-se de uma abordagem que, partindo do aprendizado social, busca apoiar-se não apenas na participação popular democrática no processo de planejamento urbano e regional, mas também na governança desse processo por meio de órgãos consultivos e deliberativos. Cabe à Universidade fomentar essa participação popular propondo atividades de extensão que unam diferentes saberes, produzindo informação e desenvolvendo mobilização política, fatores fundamentais para o sucesso de planos de desenvolvimento.

O Plano Diretor de Desenvolvimento Integrado (PDDI) e o Macrozoneamento da $\mathrm{RMBH}$, frutos desse processo, tratam de forma singular a dimensão ambiental do planejamento urbano, considerando áreas verdes, águas e cultura como fundamentais para o processo de reestruturação de territórios e ambientes construídos, em particular para a regulação urbana e fundiária. $\mathrm{O}$ artigo "Development? Thinking the future through an ur- 
ban-natural perspective, de Harley Silva, Jakob Sparn e Renata Guimarães Vieira, resultado da mesa-redonda - "Urbanização, Natureza e Alternativas para um Desenvolvimento Emancipatório no Sul Global”, oferece uma análise crítica da dinâmica industrial de crescimento urbano contemporâneo, apontando para a urgência do desenvolvimento ambiental e cultural sustentável como forma de resistência. Ao colocar em foco a ideologia de progresso e de modernidade subjacente à lógica do desenvolvimento econômico típica do pós-guerra, o trabalho chama a atenção para os desafios assim impostos para o Sul Global, em particular no que concerne aos extratos sociais marginalizados e ao meio-ambiente, que se materializam em condições precárias de bem-estar social e degradação ambiental. Nesse contexto, o conhecimento local e as soluções para problemas cotidianos práticos foram sendo diluídos pela imposição da lógica industrialista ocidental e por seu aparato técnico-científico, imprimindo esquemas de produção e reprodução que aumentam as desigualdades sociais. É sob essa perspectiva que os autores analisam o surgimento da utopia urbana, em especial a politização do espaço, como oposição à força homogeneizadora da indústria. Em vista desses movimentos de reafirmação do urbano, do social e do ambiental, é imperativo que essas dimensões sejam incorporadas nos processos de planejamento e desenvolvimento urbano e regional.

Fica claro, assim, que a cidade é o local privilegiado da criação, da produção e da reprodução, organizando o crescimento e o desenvolvimento contemporâneos, mas estando sujeita a dinâmicas externas que promovem a exploração do patrimônio natural e o aumento das desigualdades sociais. Nesse sentido, os artigos subsequentes deste número especial selecionados a partir das sessões ordinárias do 17o Seminário sobre Economia Mineira - se debruçam sobre determinantes específicos da função das cidades no processo de desenvolvimento, discutindo temas como: os efeitos da exploração dos recursos naturais sobre a gestão territorial; a influência da financeirização, como lógica de reprodução capitalista, sobre a exploração de recursos naturais e a conformação de centralidades urbanas; e a função da cidade como plataforma criativa.

O artigo "A gestão do território em áreas mineradas: questões sociais, econômicas, históricas e ambientais: o caso da mina morro da mina e a escola meridional, em Conselheiro Lafaiete, MG" de autoria de Larissa de Souza Silva e Fabiana Oliveira Araújo, oferece uma análise sobre os impactos da exploração mineral na gestão do território. Partindo da influên- 
cia exercida pela operação de mineradoras na produção do espaço e na gestão do território, o artigo discute os conflitos advindos, por um lado, da grande dependência de municípios predominantemente extrativistas em relação às atividades econômicas e receitas geradas pela exploração mineral e, por outro, das desigualdades e marginalizações provocadas pela negligência das questões sociais, culturais e históricas, decorrente do forte poder da lógica produtiva sobre a governabilidade das instituições locais. O caso da Mina do Morro, em Conselheiro Lafaiete, é emblemático ao permitir vislumbrar formas de planejamento que conciliem atores diversos, os impactos da exploração mineral, a preservação ambiental e o desenvolvimento econômico.

Dado que a função da cidade como locus do (desigual) desenvolvimento contemporâneo passa necessariamente por significativa influência de fenômenos globais, esse número especial de Nova Economia também oferece artigos que analisam os impactos da crescente financeirização das relações econômicas e sociais sobre o cotidiano urbano. $\mathrm{O}$ artigo de Ana Carolina Campos de Melo e Ana Cláudia Cardoso, intitulado "O papel da grande mineração e sua interação com a dinâmica urbana em uma região de fronteira na Amazônia", remete mais uma vez aos impactos da exploração de recursos naturais sobre o urbano, agora ressaltando a lógica da financeirização como organizadora da ocupação e exploração do espaço. A financeirização remete à crescente significância dos motivos, atores e práticas financeiras na operação das economias. $O$ estudo proposto se fundamenta na ideia de que a financeirização imprime uma nova forma de organização e operação das empresas, que passam a privilegiar os ganhos provenientes de circuitos financeiros em contraposição às receitas derivadas de processos produtivos. Essa lógica se estende a diversos mercados, inclusive os imobiliários, permitindo tornar móvel, através da securitização, um ativo que é essencialmente imóvel: a terra. Assim, empresas multinacionais que dominam setores mineiro-metalúrgicos acabam por articular diretamente os territórios de extração aos circuitos globais de acumulação. Esse é o caso da fronteira amazônica, onde as formas de operacionalização do capital alteraram a estruturação urbana e o relacionamento urbano-rural, com isso esgarçando o tecido social e ambiental. $\bigcirc$ artigo de Melo e Cardoso especifica as conexões relacionais do urbano com os níveis global e local, permitindo a construção de paralelos entre a extração de minério de ferro na Serra dos Carajás e a exploração de ouro na região do Vale do Huasco, norte do Chile. 
O mesmo processo de financeirização, com impactos significativos sobre a vida cotidiana dos cidadãos urbanos, é analisado por Anderson Cavalcante, Renan Almeida e Nathaniel Bakker em "The urban dynamics of financial services: centralities in the metropolis". Nesse artigo, a proposta é entender, a partir da teoria de aglomeração e lugar central, a formação de centralidades financeiras urbanas e a organização espacial de uma metrópole. Com a financeirização como pano de fundo, o acesso e uso de serviços financeiros passa a ser cada vez mais significativo na vida cotidiana, com efeitos próprios e específicos na organização das cidades e seus espaços. A partir da evolução da distribuição espacial das agências bancárias e dos postos de atendimento bancário na $\mathrm{RMBH}$, os autores exploram possíveis padrões e relações entre renda, população, preço de imóveis e centralidades financeiras. Tal análise é importante para a compreensão da evolução de centralidades urbanas, fator crucial para a formulação de um planejamento urbano que proporcione maior equilíbrio estrutural ao desenvolvimento metropolitano.

Por fim, o último artigo deste volume ressalta a cidade como plataforma criativa e analisa a aglomeração e formação de clusters criativos regionais no Brasil. Gabriel Vaz de Melo e Guilherme Leite Paiva oferecem o artigo "Desenvolvimento e potencial de clusters criativos para as cidades médias brasileiras", no qual a lógica das economias de aglomeração e amenidades urbanas é aplicada ao entendimento de clusters de atividade criativa, com o objetivo de identificar o potencial de desenvolvimento destes últimos em cidades médias brasileiras. A partir da discussão de possíveis tipologias e padrões derivados da análise, é possível destacar o potencial de cidades como loci de estoques e fluxos de conhecimento, em um processo de criação de trabalho novo que proporciona crescimento e desenvolvimento. A análise empírica foi capaz de destacar seis clusters criativos no Brasil, com certa preponderância de um padrão que indica a importância do tamanho da população, do grau de escolaridade, do número de amenidades culturais físicas existentes, e das manifestações culturais. A análise desses resultados pode servir como apoio para avaliação de políticas focadas na economia criativa e seus impactos, e também para o desenho de estratégias de complementação, diversificação ou especialização das cidades, em particular na formação de centralidades regionais, que afetam a estrutura da rede de cidades brasileiras.

Ao fim da leitura deste número especial de Nova Economia, fica claro que o compêndio de artigos oferece relevante e atual discussão sobre 
o desenvolvimento socioeconômico brasileiro. $\mathrm{Na}$ atual situação de crise econômica que vive o país, entre seus inúmeros dilemas, um dos principais reside na escolha de um modelo de crescimento e desenvolvimento apropriado. Independente de matrizes ideológicas, é indispensável que esse modelo esteja ancorado em instituições sólidas, que entendam que muitas das mazelas do país passam por nossas enormes desigualdades, e que estas, por sua vez, se materializam no espaço, tornando fundamental centrar a discussão sobre as nossas cidades. É grande, portanto, a contribuição do volume que agora thes apresentamos ao permitir imaginar novos caminhos para o desenvolvimento, não apenas por discutir as instituições do planejamento, mas também por indicar importantes aspectos que devem ser plenamente integrados à sua atuação, caso o desenvolvimento desejado seja aquele capaz de gerar equilíbrio sócio-ambiental-cultural. Esperamos, portanto, que o presente número especial possa servir como um guia para que formuladores de políticas públicas e instituições de desenvolvimento - como o BDMG - possam traçar novos e prósperos rumos para o país e para o estado de Minas Gerais.

Tenham todos uma agradável leitura. 